\title{
Risk Tolerance Estimation Bias: The Age Effect
}

John E. Grable, Kansas State University, USA

Samantha McGill, Kansas State University, USA

Sonya Britt, Texas Tech University, USA

\begin{abstract}
Older individuals are generally assumed to be less risk tolerant compared to others. The purpose of this research was to test how accurately working adults at different ages in the lifespan estimate their risk-taking propensity. Differential predictions, using ANOVA and regression analyses, were assessed. Findings suggest that younger working adults tend to over-estimate their risk tolerance compared to older working adults. Although those in middle-age were shown to under-estimate their risk tolerance compared to the youngest working adults, the results were not significant. A discussion of findings is presented with the proposition that over- and under-estimation of risk tolerance might help explain the types of risk-taking behaviors engaged in by individuals over time.
\end{abstract}

Keywords: Risk Tolerance, Estimation Bias, Differential Prediction

\section{INTRODUCTION}

early all researchers and financial services practitioners working in the personal and household
finance field acknowledge that financial risk tolerance, which is generally defined as a person's
willingness to engage in a financial behavior in which the outcomes are uncertain (Grable, 2008), differs among people based on age. In particular, the most common assumption stipulates that older individuals are less risk tolerant than younger persons. Although there is an ongoing debate regarding the risk tolerance-age relationship, with some arguing that there is no age-risk tolerance association (Chaulk, Johnson, \& Bulcroft, 2003) or that risk tolerance increases with age, very few studies have addressed the issue of differential prediction associated with the risk tolerance-age association. The purpose of this study was to address this need in the literature. Specifically, differential prediction, as conceptualized in this study, deals with how accurately working adults at different ages in the lifespan are able to estimate their risk-taking propensity.

As suggested above, the general consensus suggests that older individuals are less risk tolerant than others (Coleman, 2003; Halek \& Eisenhauer, 2001). While this may or may not be true - and as a result, worthy of additional research - a more intriguing question is the one that asks if people tend to over- or under-estimate their risk tolerance as they age. It might be possible, for instance, for a young person to over-estimate their risk tolerance. If mis-estimation occurs, this could lead younger working adults to take financial risks that exceed their psychometrically measured willingness to incur uncertainty and volatility in their household portfolio. The result could be financially problematic - e.g., selling assets at a loss or incurring excess debt in comparison to income and assets. It is equally possible that the phenomenon of risk tolerance decreasing with age may be an artifact of the way risk tolerance is sometimes measured. Often research reporting an inverse relationship between age and risk tolerance is based on responses to single-item risk measures. Typically, these single-item assessment tools gauge only one dimension of risk. For whatever reason, people may answer these single-item measures without considering their psychometrically accurate level of risk tolerance. In other words, a person responding to common types of risk questions may estimate that their risk tolerance is, in fact, higher or lower than it really is. The impact of mis-estimation can be particularly detrimental for older adults. If, say, an older working adult is attempting to save for retirement and they develop and manage a portfolio based on a quick self-estimation of their risk tolerance - often by comparing themselves to a fictional other person - the level of risk taken may be greater (lesser) than the 
risk appropriate given their underlying risk attitude. If it turns out that older adults, on the average, under-estimate their risk tolerance, portfolios may be developed that do not provide sufficient returns to meet long-term goal expectations.

The remainder of this paper provides an overview of the literature in the field of attitudinal self-assessment, over-confidence and estimation bias, and factors associated with the prediction of risk tolerance. This is followed by the presentation of ANOVA and regression analyses that test differential predictions associated with the risk tolerance-age association. The paper concludes with a discussion of findings.

\section{REVIEW OF LITERATURE}

\section{Attitudinal Self-Assessment}

The literature associated with personality and attitudinal assessment is expansive. A small sub-section within this literature is devoted to understanding how well people are able to estimate their own or someone else's personality or attitudes. It is important to note, however, that much of this literature has been devoted to testing how well people estimate characteristics of others. Furnham (1990) was among the first to look at the issue of selfestimation. In his research, Furnham noted that of 15 personality dimensions tested, subjects in his study were able to accurately assess 10 of these. Some attitudinal and personality constructs appear to be easier for people to estimate than others (Chamorro-Premuzic, Furnham, \& Moutafi, 2004). Furnham and Chamorro-Premuzic (2004) noted statistically significant positive correlations between estimated and measured test scores related to Agreeableness $(r=.27)$, Depression $(r=.58)$, Assertiveness $(r=.51)$, Need for Achievement $(r=.45)$ and other similar constructs. On the other hand, certain personality constructs appear to be more difficult for people to estimate. Specifically, Furnham and Chamorro-Premuzic found that people were not as accurate in estimating their Impulsivity $(r=.06)$, Vulnerability $(r=.16)$, or Excitement Seeking $(r=.26)$. These three aspects of personality tend to be related to risk tolerance, which implies that individuals may estimate their risk tolerance at a similar low level of accuracy (Roszkowski \& Grable, 2005).

The literature devoted to the testing of individuals' accuracy in estimating financial risk-tolerance, in comparison to the general personality literature, is quite small; however, a number of studies have been conducted that address this important issue. Much of this literature suggests that people tend to systematically under-estimate their own risk tolerance when compared to hypothetical others (Hsee \& Weber, 1997). Consider a study designed by Hallahan, Faff, and McKenzie (2004). They compared self-estimated risk tolerance to scores on a 25 -item risktolerance scale. Results from their study indicated that $73 \%$ of respondents under-estimated their risk tolerance while only $23 \%$ over-estimated and $4 \%$ accurately estimated their tolerance for risk.

Roszkowski and Grable (2005) examined the issue of risk-tolerance estimation by comparing self ratings with actual scores on a reliable and valid risk-tolerance scale. They found that financial planners (i.e., professional advisors with knowledge and experience in the financial markets) were able to reasonably estimate their psychometrically assessed risk tolerance $(\mathrm{r}=.63)$; however, they noted that clients of financial planners did an even better job of estimating their own risk tolerance $(r=.77)$. Roszkowski and Grable noted that the estimation process used by individuals is influenced by spurious variables and associations. Further, people tend to rely on heuristic judgments, which almost always lead to inconsistency in estimations. They presented an even more sobering conclusion by stating that computer programs can outperform human judges in predicting (estimating) risk tolerance - even one's own risk tolerance. This, again, is the result of people placing too much importance on extraneous variables, such as one's demographic profile, perceived knowledge, and other environmental factors (Payne, Bettman, \& Luce, 1998).

Moreschi (2005) used the results from the Hallahan et al. (2004) study as a starting point to examine how well survey respondents were able to predict their own risk tolerance. He calculated a person's over- or underestimation of risk tolerance by subtracting self-assessed risk tolerance from a risk-tolerance scale score. Moreschi noted a similar pattern of estimation bias that was documented by Hallahan et al. That is, four percent accurately assessed their risk tolerance, while $23 \%$ overestimated and $73 \%$ underestimated their risk tolerance. He concluded his study by suggesting that forecast errors tend to increase with age and income, but decrease for males 
and those with more education. Grable and Roszkowski (2007) also tested the relationship between self-estimated risk tolerance and actual risk tolerance. They looked at the issue of self-assessment by women and men. They found that women systematically under-estimated their psychometrically measured risk tolerance, while men overestimated their tolerance for risk. This finding held true even when accounting for confounding factors such as age, household income, marital status, and education.

When viewed broadly, the attitudinal self-assessment literature indicates that in some respects, people do a fairly good job of estimating their actual or true general personality traits and constructs. People do less well when estimating aspects of their personality related to impulsiveness, vulnerability, action-sensation seeking, and other factors generally associated with financial risk tolerance. The literature that does exist has generally failed to examine the issue of estimation accuracy beyond the broad implication that people, in general, are more likely to under-estimate their risk tolerance than to engage in over-estimation. Beyond evidence suggesting gender differences when estimating risk-tolerance, there is a paucity of substantiation to indicate other potential differences. Obtaining a better understanding of estimation accuracy related to age - an important determinant of risk tolerance adds to the existing body of literature.

\section{Overconfidence and Estimation Bias}

It is quite common for people to be overconfident in their predictions of future actions and events, even in cases where base rate probabilities might indicate outcomes that deviate from the prediction (Nowell \& Alston, 2007; Sitkin \& Pablo, 1992). Overconfidence is closely related to the concept of estimation bias. According to Griffin, Dunning, and Ross (1990), "Overconfident behavioral predictions and trait inferences may occur because people make inadequate allowance for the uncertainties of situational construal" (p. 1128). This is particularly true in relation to social prediction. Dunning, Griffin, Milojkovic, and Ross (1990) noted that people's confidence in their subjective assessment of an individual or situation greatly surpasses their objective accuracy. It appears that people interpret the meaning of an ambiguous situation based on their available knowledge and experience. Once the initial construed meaning has been established it becomes very difficult to alter the interpretation, and as a result, future assessments or evaluations tend to follow the initial interpretation. This means that it is probable that someone who uses their knowledge and experience to initially over- or under-estimate the variability in a situation will likely carry this mis-estimation into assessments of their own feelings and attitudes about risk scenarios.

Within the field of judgment and decision making this phenomenon is known as overconfidence. Overconfidence is a universal cognitive trap (Plous, 1993). Plous made a telling point when he stated that "discrepancies between accuracy and confidence are not related to a decision maker's intelligence" (p. 219). In other words, experts are as likely to engage in over- or under-estimation, with confidence, than those with little training, knowledge, or expertise. The evidence, to date, suggests that overconfidence can be reduced when the person making the estimation is provided immediate feedback regarding their evaluation (Arkes, Christensen, Lai, \& Blumer, 1987). This implies that age may play a factor in leading a person to over- or under-estimate their risk tolerance. Specifically, over- or under-estimation results from overconfidence in one's interpretation of a situational context (Lopes, 1997). It is likely that young working adults, for instance, may lack the judgment to apply accurate estimations to situations because they have, on the average, not received sufficient timely feedback over their short lifespan. In the context of financial risk tolerance, this may result in over-estimation of one's own risk tolerance when compared to a psychometrically developed risk-scale score. On the other end of the age spectrum, older working adults may be equally overconfident in under-estimating their risk tolerance. Why? Again, overconfidence stems from one's interpretation of a situation. Interpretation, as Griffin et al. (1990) noted, is based, in part, on a person's knowledge, experience, and beliefs. An older working adult will have had, by definition, more varied and complex financial experiences and information feedback than a younger working adult. The combination of these experiences will most likely influence the way risk is defined and interpreted. If someone impulsively evaluates their risk tolerance without overtly considering their past experiences and knowledge gained from such experiences, the concept of risk may be interpreted to mean loss, especially to an older working adult with more knowledge and experience in the financial markets. Since the concept of loss is almost always construed as negative, an older working adult, more so than a younger person who is likely to evaluate risk not as loss but as excitement, may be more likely to confidently under-estimate their risk tolerance. 
Overconfidence has also been attributed to an illusion of control exhibited by certain decision makers (Langer \& Roth, 1975; Sjoberg, 2000). The tendency to believe that risk can be controlled often leads to reduced levels of risk aversion. Langer (1975) found that younger people, in particular, have a propensity to believe that they have more control over situations than they actually do. Greene, Krcmar, Rubin, Walters, and Hale (2002) noted that young people, while having the knowledge to perceive risks, do not incorporate risk into their decision-making processes the same way as older adults. This may be attributable to an inclination to create 'personal fables' around risk issues. Alberts, Elkind, and Ginsberg (2007) argued that it is common, especially among young people, to believe that they are uniquely individual and immune from the outcomes associated with risky decisions - i.e., a personal fable. Personal fables help create a sense of invulnerability, which can often lead to overconfidence in risky situations. A corollary to this argument is the one that states overconfidence results, in part, from the belief that knowledge alone is sufficient to mitigate risk. According to Russo and Schoemaker (1992), "Good decision making requires more than knowledge of facts, concepts, and relationships. It also requires metaknowledge - an understanding of the limits of our knowledge" (p. 7). It appears that women and those with less attainted education do a better job of recognizing the limits of their knowledge than men and those with higher educational status (Wright, Pearman, \& Yardley, 2000). In other words, women are more likely to be less optimistic than men (Camerer \& Lovallo, 1999); males generally exhibit overconfidence throughout the domain of risk decisions. Further, overconfidence is more generally associated with increased attained education, although Nowell and Alston (2007) found in their study that students with lower GPAs exhibited greater overconfidence than others. The more common education-overconfidence relationship may be attributable to perceptions of decision-making difficulty in risky situations. Hoelzl and Rustichini (2005) noted that those who perceive a task as being easy exhibit higher levels of overconfidence than when a task is not familiar and difficult. A person's educational level and age may impact these perceptions.

As the literature illustrates, overconfidence is a widely recognized bias among people of all ages and demographic backgrounds. Sometimes overconfidence manifests itself as under- or over-estimation of risk tolerance. It is reasonable to hypothesize that younger working adults are almost always more susceptible to overestimation of their financial risk tolerance. Older working adults, on the other hand, can be thought of as more likely to under-estimate their risk tolerance. Findings from this study help address this hypothesis.

\section{Factors Associated with Risk Tolerance}

A recent review of individual and environmental factors associated with financial risk tolerance was compiled by Grable (2008). Based on an analysis of 125 studies published between 1960 and 2006, he was able to identify factors assumed to be related to a person's willingness to engage in risky financial behaviors. Several factors and their association with risk tolerance in Grable's analysis were found to have strong support in the literature. Gender was one such variable. In general, males are known to be more risk tolerant, both in general terms and when making financial decisions, than women. Consider findings reported by Bajtelsmit, Bernasek, and Jianakoplos (1999). Bajtelsmit and her associates found that women exhibit more risk aversion (i.e., less risk tolerance) when allocating assets in defined contribution plans. A similar general gender-financial risk-tolerance association has been noted by Ardehali, Paradi, and Asmild (2005) and others (e.g., Halek \& Eisenhauer, 2001; Nairn, 2005; Yao \& Hanna, 2005). Grable and Roszkowski (2007) used these research insights to determine that men are not only more risk tolerant than women, they also tend to over-estimate their proclivity for taking risks.

Besides gender, age is the most widely studied factor generally thought to be associated with financial risk tolerance. The general consensus indicates that younger working adults should be more risk tolerant than older employed adults. According to Grable (2008), there is a moderate level of support for this assertion within the literature. Deaves, Veit, Bhandari, and Cheney (2007) reported that the negative association between age and risk tolerance is also apparent when actual behaviors, rather than attitudes, are noted. Nairn (2005) summarized the relationship this way: "The general pattern is for older customers to be more risk averse" (p. 383). On the other hand, Ardehali et al. (2005) found the age-risk tolerance association to be weak at best and at some points in the age life span "not conclusive at all" (p. 508). They noted a distinct possibility of risk tolerance increasing more than once during the lifespan. Whether or not differences in personal risk-tolerance estimation occur based on age, or if people are just as likely to under-, over-, or accurately estimate their risk tolerance throughout the lifespan is a question that has yet to be answered in the literature. 
Three other personal characteristics, in addition to gender and age, are commonly used as confounding factors within studies designed to test risk-tolerance research questions. The first, household income, has moderate support as a determinant of risk tolerance in the literature (Grable, 2008). When viewed from a general risk-taking perspective, Slimak and Dietz (2006) concluded that individuals who are financially well-off tend to be less concerned about risk items. A positive association between income and risk-tolerance has been noted by others (e.g., Ardehali et al., 2005; Deaves et al., 2007; Nairn, 2005). In effect, income appears to act as a buffer between a person and the potential shocks associated with losing money via a financial decision. The second variable, marital status, also has moderate support in the literature as a factor influencing risk tolerance. The consensus opinion is that single individuals are more risk tolerant than married persons (Yao \& Hanna, 2005). Ardehali and his associates hypothesized that this may be the case because those who are married may perhaps feel that a monetary loss resulting from a financial decision could negatively impact their family and relationship, and as a result, married individuals may shy away from taking risks. Ardehali et al. found support for their hypothesis. They noted that singles are more risk tolerant (less risk averse) than married individuals. The third variable, attained educational level, like income and marital status, has moderate support in the literature as a factor that influences financial risk tolerance. Most commonly, education is presumed to be positively associated with risk tolerance. More specifically, those holding at least a bachelor's degree level of education are thought to be more risk tolerant than others, with people who have a high school diploma or less having the lowest risk tolerance (Grable, 2008; Halek \& Eisenhauer, 2001). Riley and Chow (1992) pointed out that the relationship may actually be the result of wealth accruing from higher income generated from education rather than education alone. Ardehali et al. concurred and hypothesized that education can sometimes be used as a proxy for human capital. In their study, education was associated with increased financial risk tolerance.

As this review of literature illustrates, the risk-tolerance literature, as it relates to personal finance topics, is replete with reports which suggest that men are more risk tolerant than women; that household income is positively associated with risk tolerance; that those who are married tend to be less risk tolerant than others; and that attained educational levels are positively associated with a person's willingness to take risks. There is also ample evidence to indicate that a person's age influences their risk tolerance. The general consensus advocates the position that risk tolerance decreases with age; however, this is not a universally supported conclusion (Grable, 2008). An important question remains to be answered, namely, if factors such as gender, household income, marital status, and education are accounted for, will age differences in risk-tolerance estimation emerge? The remainder of this paper addresses this specific question.

\section{METHODOLOGY}

\section{Sample Characteristics}

Data for this study were collected from a sample of convenience. Potential respondents resided in one of three municipalities within one Midwestern U.S. state. Two of the communities were moderate sized towns, while the third was a large metropolitan area. Overall, the demographic profile of the final sample $(N=466)$ can best be described as a well-educated non-Hispanic White affluent female. Approximately $27 \%$ of respondents were male. Nearly $27 \%$ reported having a high school degree; $33 \%$ reported having some college or vocational training; $35 \%$ held a bachelor's degree; and $22 \%$ reported having a graduate or professional degree. Respondents' household incomes fell within a median range of $\$ 50,001$ to $\$ 60,000$. On average, respondents were likely to be married (65\%), racially homogenous (94\% non-Hispanic White), and apt to own their own home (75\%). The average household size for respondents was three persons. Respondents were, on the average, 45 years of age ( $S D=12$ years). When split into age quartiles, $26 \%$ of respondents fell between 0 to 35 years, $25 \%$ were between 35.1 to 45 years, $28 \%$ fell between 45.1 to 53 years, with the remainder (21\%) being 53.1 years and older.

\section{Data Analysis Method}

A differential prediction model technique was used to determine if self-estimations of risk tolerance differed based on age. Residual risk-tolerance scores (values) were calculated first by having respondents answer the following question by selecting the description that best represented their attitude: "In general, how would your best friend describe you as a risk taker? (a) A real gambler; (b) Willing to take risks after completing adequate research; 
(c) Cautious; or (d) A real risk avoider." The validity of this question has been tested with the result being that it serves well as a quick one-time risk-assessment tool (Grable, Roszkowski, Joo, O’Neill, \& Lytton, in press). Scores were assigned as follows: Real gamblers received a score of 4.0; those who were willing to take risks after adequate research received a score of 3.0; those who were cautious received a score of 2.0; real risk avoiders received a score of 1.0. The mean score for the sample on this item was $2.24(S D=.64)$.

Respondents were then asked to complete a 12-item risk-tolerance assessment instrument $(\alpha=.70)$. The 12 items were adapted from Grable and Lytton's (1999) risk-tolerance scale. Examples of questions asked include the following:

When you think of the word "risk" which of the following words comes to mind first?
a. Loss
b. Uncertainty
c. Opportunity
d. Thrill

Some experts are predicting prices of assets such as gold, jewels, collectibles, and real estate (hard assets) to increase in value; bond prices may fall, however, experts tend to agree that government bonds are relatively safe. Most of your investment assets are now in high interest government bonds. What would you do?

a. Hold the bonds

b. Sell the bonds, put half the proceeds into money market accounts, and the other half into hard assets

c. Sell the bonds and put the total proceeds into hard assets

d. Sell the bonds, put all the money into hard assets, and borrow additional money to buy more

Given the best and worst case returns of the four investment choices below, which would you prefer?

a. $\$ 200$ gain best case; $\$ 0$ gain/loss worst case

b. $\$ 800$ gain best case; $\$ 200$ loss worst case

c. $\$ 2,600$ gain best case; $\$ 800$ loss worst case

d. $\$ 4,800$ gain best case; $\$ 2,400$ loss worst case

Scores ranged from a low of 13.0 to a high of 33.0. The mean risk-tolerance score was $21.77(S D=4.17)$. The 12-item summated risk score for each respondent was used to predict self-rating assessment scores. The unstandardized predicted values from the regression were saved for each respondent. Each respondent's predicted risk-tolerance score was then subtracted from their actual self-rating score. The result was a residual risk-tolerance score for each respondent.

Residual values were then saved for each person who responded to the survey. Residual values ranged from a low of -1.70 to a high of 2.11. As shown in Table 1 , the mean residual value was $.01(S D=.60)$. The residual value indicates the amount by which a respondent either over- or under-estimated their psychometrically assessed risk tolerance (Linn, 1978). A positive (+) residual value indicated an over-estimation. A negative (-) residual value suggested an under-estimation. This information was used in ANOVA and regression models to test whether or not systematic age differences existed in relation to over- or under-estimation of risk tolerance.

\section{RESULTS}

For reference purposes, it is useful to note that the median age of respondents was 45 years. The age of those responding to the survey ranged from 21 to 86 years. In order to answer the question of interest in this 
research, age quartiles were calculated for the sample. The first quartile included respondents up to and including age $35(\mathrm{n}=123)$; the second quartile encompassed those older than 35 years but less than or equal to 45 years $(\mathrm{n}=$ 116); the third quartile included those older than age 45 but less than or equal to age $53(n=128)$; the final quartile consisted of those older than age $53(\mathrm{n}=99)$. Minimum and maximum risk-tolerance residual values were as follows: first quartile: -1.60 and 1.75 , respectively; second quartile: -1.40 and .95 , respectively; third quartile: -1.65 and 2.11, respectively; fourth quartile: -1.45 and 1.75, respectively. An ANOVA test was conducted to compare the mean residual values among the four age groups. The overall $F$ value for the one-way ANOVA was statistically significant, $F(3,462)=2.79, p<.05$. Although the effect size was small (.02), post-hoc tests (i.e., Tukey and Bonferroni) showed the greatest mean residual value differences between the youngest group (i.e., first quartile) and oldest group (i.e., fourth quartile). The mean difference was .22 points. No significant residual values were noted between or among the other age categories.

Table 1 shows descriptive statistics for the sample based on age used in the ANOVA test. As a sample, respondents, on average, did a relatively good job of estimating their psychometrically assessed level of risk tolerance (column 2). The mean residual value was close to zero for the sample as a whole. However, respondents who were 35 years of age or younger tended to over-estimate their risk tolerance $(M=.09)$. At the other end of the age spectrum, respondents who were older than 53 years of age (column 10) tended to under-estimate their risk tolerance $(M=-.13)$. The difference between the over- and under-estimation was statistically significant. No statistically significant residual value differences were noted for those in middle age.

Table 1: Descriptives for Sample based on Age: Percent

\begin{tabular}{|c|c|c|c|c|c|c|c|c|c|c|}
\hline \multirow[t]{2}{*}{ Variable } & \multicolumn{2}{|c|}{ Sample } & \multicolumn{2}{|c|}{ Age: $0-35$} & \multicolumn{2}{|c|}{ Age: $35.1-45$} & \multicolumn{2}{|c|}{ Age: $45.1-53$} & \multicolumn{2}{|c|}{$\begin{array}{c}\text { Age: } 53.1 \text { \& } \\
\text { Older }\end{array}$} \\
\hline & $M$ & $S D$ & $M$ & $S D$ & $M$ & $S D$ & $M$ & $S D$ & $M$ & $S D$ \\
\hline $\begin{array}{l}\text { Self-Assessed Risk Tolerance, } \\
\text { point }\end{array}$ & .074 & .262 & .063 & .244 & .064 & .246 & .075 & .264 & .093 & .291 \\
\hline Real Gambler & .535 & .499 & .449 & .499 & .592 & .493 & .500 & .502 & .611 & .490 \\
\hline Willing After Research & .373 & .484 & .449 & .499 & .344 & .477 & .403 & .492 & .287 & .454 \\
\hline Cautious & .018 & .133 & .039 & .195 & .000 & .000 & .022 & .149 & .009 & .096 \\
\hline $\begin{array}{l}\text { Risk Avoider } \\
\text { 12-Item Risk Scale, points }\end{array}$ & 21.768 & 4.166 & 22.350 & 3.919 & 21.147 & 3.902 & 21.789 & 4.203 & 21.717 & 4.623 \\
\hline Risk-Tolerance Residual Value & .010 & .603 & .089 & .647 & -.013 & .527 & .045 & .617 & -.132 & .578 \\
\hline Gender $(1=\text { Male })^{*}$ & .267 & .443 & .291 & .456 & .260 & .441 & .286 & .453 & .314 & .466 \\
\hline Household Income & 5.317 & 2.448 & 4.079 & 2.294 & 5.696 & 2.266 & 5.649 & 2.360 & 5.528 & 2.512 \\
\hline $\begin{array}{l}\text { Marital Status }(1=\text { Married })^{*} \\
\text { Education }\end{array}$ & .649 & .478 & .581 & .495 & .634 & .484 & .679 & .469 & .692 & .464 \\
\hline High School or Less & .267 & .444 & .261 & .449 & .192 & .398 & .254 & .439 & .353 & .483 \\
\hline Some College & .334 & .472 & .173 & .380 & .440 & .498 & .381 & .487 & .342 & .477 \\
\hline Bachelor's Degree & .346 & .476 & .528 & .501 & .336 & .474 & .276 & .449 & .232 & .424 \\
\hline Graduate Degree & .219 & .414 & .252 & .436 & .144 & .352 & .231 & .423 & .259 & .440 \\
\hline
\end{tabular}

Note. Mean averages may not sum to 1.00 due to rounding. *Mean refers to percent who are male or married, respectively.

Grable and Roszkowski (2007) noted a similar relationship between risk-tolerance residual values and a person's gender. In their study, men tended to over-estimate their risk-taking propensity while women underestimated their risk tolerance. Their initial findings were based on bivariate statistical tests. Grable and Roszkowski recommended that a "more rigorous multivariate test" (p. 799) be applied to similar examinations of risk-tolerance residual values in order to obtain results that account for possible confounding factors. It was hypothesized that in this study a person's gender, household income, marital status, or educational level might alter the conclusion derived from the ANOVA test.

Two regression analyses were conducted to further test the risk-tolerance residual ANOVA findings. Table 2 shows the regression analysis for variables predicting risk-tolerance residual values using age, gender, household income, marital status, and education as independent variables. Note that in this regression, age was used as an 
interval-level variable. Results illustrate that when other factors were held constant, older respondents were slightly more likely than not to under-estimate their psychometrically assessed level of risk tolerance. Although the finding was statistically significant, the effect size was small $\left(s r^{2}=-.16\right)$. The only other variable that was significant was marital status. Married respondents were much more likely to under-estimate their risk tolerance than single respondents.

Table 2: Summary of Regression Analysis for Variables Predicting Residual Value Risk Tolerance

\begin{tabular}{lccc}
\hline \multicolumn{1}{c}{ Variable } & B & SE B & $\beta$ \\
\hline Age & -.008 & .002 & $-.165^{* *}$ \\
Gender (1 = Male) & .023 & .061 & .018 \\
Household Income & .011 & .013 & .044 \\
Marital Status (1 = Married) & -.162 & .063 & $-.131^{*}$ \\
Education & & & .049 \\
$\quad$ Some College & .062 & .101 & .062 \\
$\quad$ Bachelor's Degree & .078 & .103 & .080 \\
$\quad$ Graduate Degree & .114 & .110 & .147 \\
Constant & .333 & & \\
\hline
\end{tabular}

Note. $R^{2}=.048 . * p<.01 . * * p<.001$.

A second regression was run (Table 3) to determine if age category differences, such as those found in the ANOVA test, held true when other factors were accounted for in the model. Using the first quartile group (i.e., youngest respondents) as the omitted category, the oldest respondents (i.e., those in the fourth quartile) were significantly more likely to under-estimate their risk tolerance. This finding supported the ANOVA test. No significant differences were noted between the first and second quartile or the first and third quartile age groups; however, it is interesting to note that the unstandardized and standardized $(\beta)$ coefficients for each of the age categories was negative. This suggests that, when compared to the youngest respondents, older individuals tended to under-estimate their risk tolerance. The largest difference in risk estimation was between the youngest and oldest quartile groups. Nonetheless, age differences were apparent across all of the categories. As was the case with the first regression, those who were married under-estimated their risk tolerance.

Table 3: Summary of Regression Analysis for Variables Predicting Residual Value Risk Tolerance Using Age Categories

\begin{tabular}{lccc}
\hline Variable & B & SE B & $\beta$ \\
\hline Age & & & -.068 \\
$\quad$ 35.1 to 53 & -.094 & .083 & -.036 \\
$\quad$ 45.1 through 53 & -.048 & .079 & $-.165^{*}$ \\
$\quad-.241$ & .086 & .018 \\
Gender (1 = Male) & .024 & .062 & .029 \\
Household Income & .007 & .014 & $-.135^{*}$ \\
Marital Status (1 = Married) & -.166 & .064 & .053 \\
Education & & & .074 \\
$\quad$ Some College & .066 & .101 & .083 \\
$\quad$ Bachelor's Degree & .093 & .104 & .111 \\
$\quad$ Graduate Degree & .188 & .113 & \\
Constant & .077 & & \\
\hline
\end{tabular}

Note. $R^{2}=.048 . * p<.01$.

\section{DISCUSSION}

The research question of interest in this paper was as follows: If factors such as a gender, household income, marital status, and education are accounted for, will age differences in risk-tolerance estimation emerge? The answer to this question is not unimportant. According to Sitkin and Pablo (1992), "Risk perceptions have drawn 
scholarly attention in part because of their impact on decision makers' behavior, leading decision makers to deny uncertainty, to overestimate or underestimate risks, and to exhibit unwarranted confidence in their judgments" (p. 12). The patterns of over- and under-estimation, as shown in the ANOVA and regression tests from this study, can be used to help document and explain discrepancies in wealth accumulation over the lifespan. For example, the ANOVA test showed that the younger working adults over-estimated their level of risk tolerance in comparison to a valid and reliable measure of their risk tolerance. Might this finding help explain investing behaviors among younger working adults? The general myopic investing behaviors of younger people (Finke \& Huston, 2004) may be partially explained by risk-tolerance over-estimation. On the other hand, the oldest working adults and those who were retired - individuals with the most hands-on experiential financial market knowledge - were shown to underestimate their psychometrically assessed level of risk tolerance. This may well help explain the relative lack of savings for retirement among early and late baby boomers. Specifically, the under-estimation of risk tolerance may drive older working adults to take less risk, and as such, receive lower investment returns during their crucial preretirement savings years. This may occur particularly if older adults base their asset allocation and portfolio management decisions on personal risk-tolerance estimates rather than on psychometrically derived scale scores or other similar measurement techniques.

The findings from this study show that the youngest working adults tend to over-estimate and that the oldest working adults generally under-estimate their financial risk tolerance. This supports overconfidence patterns noted by Gervais and Odean (2001) among investors in general. They found that "the greatest overconfidence in a trader's lifespan comes early in his career. After this he tends to develop a progressively more realistic assessment of his abilities as he ages" (p. 2). Why might this be the case? It may come back to what Russo and Schoemaker (1992) call metaknowledge. In other words, young people may over-estimate the precision of their knowledge which leads to overconfidence (Barber \& Odean, 2001). The youngest working adults have not yet attained precision in their knowledge of risk and risky situations, and as such, they ought to, and most often do in practice, exhibit overconfidence in relation to their risk tolerance estimation. Gervais and Odean noted that the most overconfident people will be those who are successful and inexperienced. Those fitting this profile often confuse their success with their ability to control risk (i.e., the illusion of control). The illusion of control decreases as one ages and gains experience. So, it is not surprising that in this study the oldest working adults exhibited the greatest under-estimation bias.

The marital status finding from this study adds to the existing body of knowledge by showing that married individuals tend to under-estimate their financial risk tolerance compared to singles. Unlike the age-confidence and gender-confidence literature, there is a scarcity of writing on the marital status-confidence/estimation association. If it is assumed that a marital relationship can be viewed similarly to a corporate union, the finding that married individuals under-estimate their risk tolerance has important household financial implications (Sieck, Merkle, \& Van Zandt, 2007). According to Sieck and his associates, families stand to either make or lose money depending on the forecasts they formulate about the financial environment. If, as the findings from this study suggest, married individuals systematically under-estimate their risk tolerance they may mis-judge macro-, as well as household, economic events that can impact financial losses on the family unit. Those who under-estimate their risk tolerance may over-compensate for perceived risks in such a way that the marital unit is actually placed in a more risky situation in terms of asset accumulation, threat management, and loss control. The movement from over-estimation as a single person to under-estimation as a married person also may correspond to shifts people make when creating personal fables. As a single person it is easier to imagine that the world revolves singularly around one person; however, this lens of reality changes when a person enters a marriage. At that point, the individualist personal fable fades and is replaced by a joint view of the world and the risks associated with decisions.

Several policy and practice management implications and opportunities are linked with this research. First, on the policy side of the equation, it is important to bear in mind that "In general, optimism is greatest for hazards with which subjects have little personal experience" (Weinstein, 1989, p. 1232). Young working adults with little practical financial planning and/or investment management experience are likely to over-estimate their financial risk tolerance, and as such, engage in potentially problematic financial behaviors (e.g., payday lending, sub-prime mortgages, financial scams) while avoiding or postponing recommended saving strategies (e.g., contributing to a defined contribution retirement plan, establishing an emergency savings fund, etc.). Some may attribute this propensity to over-estimate risk tolerance as a cognitive bias resulting from the perception of risk control. It may be 
possible to develop school-based educational tools (e.g., similar to popular stock market games) that allow students to gain experience through the application of the "illusion of control" hypothesis with negative consequences. Such a game might help increase metaknowledge by allowing students to establish benchmarks for assessing the limits of their knowledge and perceptions of risk both today and later in their working life.

For financial services practitioners, the implications from this study are more straightforward. Financial advisors are cautioned to remember that the oldest working adults - those typically served by financial planners are likely to under-estimate their financial risk tolerance. The same is true for married clients. Knowing this, a financial services practitioner should take direct steps to first assess a client's financial risk tolerance and then compare this to a self-assessed measure similar to the one used in this paper or the one item available in the Survey of Consumer Finances. If an under-estimation is observed, this information can be used to help shape future advisorclient interactions. For example, the financial advisor should acknowledge that the client in this case is not matching their psychometrically accurate level of risk tolerance with their risk estimation. Providing knowledge and context for financial decisions is one way to narrow the under-estimation gap. Making financial decisions easy and familiar (Hoelzl \& Rustichini, 2005) is the surest way to mitigate risk tolerance estimation bias and increase confidence among clients.

In summary, the results from this study suggest that, as hypothesized at the outset of this paper, age differences do occur in terms of risk-tolerance estimation. Although the effect size was small, it was found that the youngest working adults in the sample exhibited marked over-estimation of their risk tolerance compared to the oldest working adults. While this finding is noteworthy, it is important to acknowledge that the results of a similar study with a different sample might produce dissimilar outcomes. Further, unless a financial services practitioner is working with a clientele group similar to the sample, the results from this study may not be generalizable. Specifically, those in the sample were, on the average, a well educated, high income, racially homogenous group. On the other hand, if a financial planner or similar advisor works with clients who fit this general profile, the results from this study may provide an insight into why older clients differ, in terms of risk tolerance, from younger clients.

\section{AUTHOR INFORMATION}

John E. Grable, is a Professor of Personal Financial Planning at Kansas State University. He serves as the Program Director for the undergraduate and graduate programs in financial planning and as the Director of the Financial Therapy Clinic at K-State. His research interests include financial risk-tolerance assessment, financial planning helpseeking behavior, and clinical approaches to financial therapy. He has been the recipient of several research and publication awards and grants, and is active in promoting the link between research and financial planning practice where he has published numerous.

Samantha McGill, is a master's degree student in Personal Financial Planning and the Director of the Consumer and Tenant Affairs office at Kansas State University. Her research interests include psychological associations between risk attitudes and behaviors.

Sonya Britt, is a doctoral student studying Personal Financial Planning at Texas Tech University. Sonya received her master's degree from Kansas State University while studying marriage and family therapy. Currently, she is an Accredited Financial Counselor and Licensed Marriage and Family Therapist. Her research interests include studying money dynamics within families.

\section{REFERENCES}

1. Alberts, A., Elkind, D., \& Ginsberg, S. (2007). The personal fable and risk-taking in early adolescence. Journal of Youth Adolescence, 36, 71-76.

2. Ardehali, P. H., Paradi, J. C., \& Asmild, M. (2005). Assessing financial risk tolerance of portfolio investors using data envelopment analysis. International Journal of Information Technology and Decision Making, 4, 491-519.

3. Arkes, H. R., Christensen, C., Lai, C., \& Blumer, C. (1987). Two methods of reducing overconfidence. Organizational Behavior and Human Decision Processes, 39, 133-144. 
4. Bajtelsmit, V. L., Bernasek, A., \& Jianakoplos, N. A. (1999). Gender differences in defined contribution pension decisions. Financial Services Review, 8, 1-10.

5. Barber, B. M., \& Odean, T. (2001). Boys will be boys: Gender, overconfidence, and common stock investment. The Quarterly Journal of Economics, 116, 261-292.

6. Camerer, C., \& Lovallo, D. (1999). Overconfidence and excess entry: An experimental approach. The American Economic Review, 89, 306-318.

7. Chamorro-Premuzic, T., Furnham, A.., Moutafi, J. (2004). The relationship between estimated and psychometric personality and intelligence scores. Journal of Research in Personality 38, 505-513.

8. Chaulk, B., Johnson, P. J., \& Bulcroft, R. (2003). Effects of marriage and children on financial risk tolerance: A synthesis of family development and prospect theory. Journal of Family and Economic Issues, 24, 257-279.

9. Coleman, S. (2003). Risk tolerance and the investment behavior of black and Hispanic heads of household. Financial Counseling and Planning, 14(2), 43-52.

10. Deaves, R., Veit, E. T., Bhandari, G., \& Cheney, J. (2007). The savings and investment decisions of planners: A cross sectional study of college employees. Financial Services Review, 16, 117-133.

11. Dunning, D., Griffin, D. W., Milojkovic, J., \& Ross, L. (1990). The overconfidence effect in social prediction. Journal of Personality and Social Psychology, 58, 568-581.

12. Finke, M. S., \& Huston, S. J. (2004). Risk and myopic financial decisions. Journal of Personal Finance 3(3), 99-112.

13. Furnham, A. (1990). Can people accurately estimate their own personality test scores? European Journal of Personality, 4, 319-327.

14. Furnham, A. \& Chamorro-Premuzic, T. (2004). Estimating one's own personality and intelligence scores. British Journal of Psychology, 95, 149-160.

15. Gervais, S., \& Odean, T. (2001). Learning to be overconfident. The Review of Financial Studies, 14, 1-27.

16. Greene, K., Krcmar, M., Rubin, D. L., Walters, L. H., \& Hale, J. L. (2002). Elaboration in processing adolescent health messages: The impact of egocentrism and sensation seeking on message processing. Journal of Communication, 52, 812-831.

17. Griffin, D. W., Dunning, D., \& Ross, L. (1990). The role of construal processes in overconfident predictions about the self and others. Journal of Personality and Social Psychology, 59, 1128-1139.

18. Grable, J. E. (2008). Risk Tolerance (pp. 1-20). In J. J. Xiao (Ed.), Advances in Consumer Financial Behavior Research. New York: Springer.

19. Grable, J. E., \& Lytton, R. H. (1999). Financial risk tolerance revisited: The development of a risk assessment instrument. Financial Services Review, 8, 163-181.

20. Grable, J. E., \& Roszkowski, M. J. (2007). Self-assessments of risk tolerance by women and men. Psychological Reports, 100, 795-802.

21. Grable, J. E., Roszkowski, M. J., Joo, S-H., O’Neill, B., \& Lytton, R. H. (in press). Self-estimated risk tolerance. International Journal of Risk Assessment and Management.

22. Halek, M., \& Eisenhauer, J. G. (2001). Demography of risk aversion. The Journal of Risk and Insurance, $68,1-24$.

23. Hallahan, T. A., Faff, R. W., \& McKenzie, M. D. (2004). An empirical investigation of personal financial risk tolerance. Financial Services Review, 13, 57-78.

24. Hoelzl, E., \& Rustichini, A. (2005). Overconfident: Do you put your money on it? The Economic Journal, 115, 305-318.

25. Hsee, C.K., \& Weber, E.U. (1997). Fundamental prediction error: Self-others discrepancies in risk preference. Journal of Experimental Psychology: General, 126, 45-53.

26. Langer, E. J. (1975). The illusion of control. Journal of Personality and Social Psychology, 32, 311-328.

27. Langer, E. J., \& Roth, J. (1975). Heads I win, tails it's chance: The illusion of control as a function of the sequence of outcomes in a purely chance task. Journal of Personality and Social Psychology, 32, 951-955.

28. Linn, R. L. (1978) Single-group validity, differential validity, and differential prediction. Journal of Applied Psychology, 63, 507-512.

29. Lopes, L. L. (1997). Between hope and fear: the psychology of risk (pp. 681-720). In W. M. Goldstein, \& Hogarth, R. M. (Eds.), Research on Judgment and Decision Making. Cambridge, UK: Cambridge University Press. 
30. Moore, D. A., \& Cain, D. M. (2007). Overconfidence and underconfidence: When and why people underestimate (and overestimate) the competition. Organizational Behavior and Human Decision Processes, 103, 197-213.

31. Moreschi, R. W. (2005). An analysis of the ability of individuals to predict their own risk tolerance. Journal of Business and Economics Research, 3(2), 39-48.

32. Nairn, A. (2005). Beyond Sandler: Risk tolerance and the UK investment deficit. Journal of Financial Services Marketing, 9, 375-389.

33. Nowell, C., \& Alston, R. M. (2007). I thought I got an A! Overconfidence across the economics curriculum. Journal of Economic Education, 38, 131-142.

34. Payne, J. W., Bettman, J. R., \& Luce, M. F. (1998). Behavioral decision research: An overview. In M. H. Birnbaum (Ed.), Measurement, judgment, and decision making (pp. 303-359). San Diego, CA: Academic Press.

35. Plous, S. (1993). The psychology of judgment and decision making. New York: McGraw-Hill.

36. Riley, W. B., Chow, K. V. (1992). Asset allocation and individual risk aversion. Financial Analysts Journal, 48(6), 32-37.

37. Roszkowski, M. J., \& Grable, J. E. (2005). Estimating risk tolerance: The degree of accuracy and the paramorphic representations of the estimate. Financial Counseling and Planning, 16 (2), 29-48.

38. Russo, J. E., \& Schoemaker, P. J. H. (1992). Managing overconfidence. Sloan Management Review, 33(2), 7-18.

39. Sieck, W. R., Merkle, E. C., \& Van Zandt, T. (2007). Option fixation: A cognitive contributor to overconfidence. Organizational Behavior and Human Decision Processes, 103, 68-83.

40. Sitkin, S. B., \& Pablo, A. L. (1992). Reconceptualizing the determinants of risk behavior. The Academy of Management Review, 17, 9-38.

41. Slimak, M. W., \& Dietz, T. (2006). Personal values, beliefs, and ecological risk perception. Risk Analysis, 26, 1689-1705.

42. Sjoberg, L. (2000). Factors in risk perception. Risk Analysis, 20, 1 -11.

43. Weinstein, N. D. (1989). Optimistic biases about personal risks. Science, 246, 1232-1233.

44. Wright, G., Pearman, A., \& Yardley, K. (2000). Risk perception in the U.K. oil and gas production industry: Are expert loss-prevention managers' perceptions different from those of members of the public? Risk Analysis, 20, 681-690.

45. Yao, R., \& Hanna, S. D. (2005). The effect of gender and marital status on financial risk tolerance. Journal of Personal Finance, 4(1), 66-85. 